Original Article

Resha Shrestha, MS

Department of Neurosurgery

Annapurna Neurological Institute and Allied Sciences

Maitighar, Kathmandu

Takaomi Taira, MD, PhD

Department of Neurosurgery

Tokyo Women's Medical University, Tokyo, Japan

Pranaya Shrestha, MS

Department of Neurosurgery

Annapurna Neurological Institute and Allied Sciences

Maitighar, Kathmandu

Pravesh Rajbhandari, MS

Department of Neurosurgery

Annapurna Neurological Institute and Allied Sciences

Maitighar, Kathmandu

Sudan Dhakal, MS

Department of Neurosurgery

Annapurna Neurological Institute and Allied Sciences

Maitighar, Kathmandu

Samir Acharya, MS

Department of Neurosurgery

Annapurna Neurological Institute and Allied Sciences

Maitighar, Kathmandu

Chandra Prakash Limbu, MS

Department of Neurosurgery

Annapurna Neurological Institute and Allied Sciences

Maitighar, Kathmandu

Basant Pant, MD, PhD

Department of Neurosurgery

Annapurna Neurological Institute and Allied Sciences

Maitighar, Kathmandu

Address for correspondence:

Resha Shrestha, MS

Departement of Neurosurgery

Annapurna Neurological Institute and Allied Sciences

Maitighar, Kathmandu

Email: reshkums@hotmail.com

Received, 16 October, 2016

Accepted, 9 November, 2016

$\mathrm{S}$ urgical treatment of Parkinsons disease(PD) is based on the changes in the basal ganglio-thalamocortical circuits which is altered in PD. Stereotactic neurosurgery for PD was introduced in 1946 and classical pallidotomy (anterodorsal) was widely used in 1950 . ${ }^{9}$ This procedure was good for rigidity but it had little effect on tremor and hypokinesia. So Lekshell modified
Nepal Journal of Neuroscience 13:68-72, 2016

\section{Result of Pallidotomy in Parkinson's Disease in Nepal}

Surgical treatment of Parkinsons disease (PD) has already been an established treatment. Currently pallidotomy, Deep Brain Stimulation (DBS) of Globus pallidus internus (GPi) and Subthalamic nucleus (STN) are available mode of surgical treatment of PD. We have included all patients of idiopathic Parkinosons disease who underwent pallidotomy in Annapurna Neurological Institute and Allied Sciences since 2014. The demographics of the patients have been shown and the patient's improvement has been shown by Unified Parkinsons Disease Rating Score (UPDRS). We have found that pallidotomy is still a promising surgical modality but it is advised to perform either unilaterally or staged bilaterally with at least 3 months gap inbetween.

Key Words: pallidotomy, parkinsons disease, UPDRS 


\section{Materials and Methods}

All patients of idiopathic Parkinson's disease who underwent pallidotomy in Annapurna Neurological Institute and Allied sciences since 2014 were included in this study. The patients undergoing Deep Brain Stimulation (DBS) for same disease were excluded. The inclusion criteria for lesioning were patients with idiopathic Parkinson's disease, dopamine responders, medically and psychologically stable patients and with drug related adverse effects like dyskinesia.

\section{Statistical analysis}

Nominal and categorical data was expressed as frequency and numerical data were expressed as median \pm Standard deviation. Statistical analysis was performed with software SPSS (version 20 IBM). Wilcoxon sign rank test was done to compare the preoperative and postoperative UPDRS Score and the difference in values was considered significant if $\mathrm{P}$ value $<0.05$.

\section{Surgical techniques}

All patients underwent Brain MRI (1.5-3 T, Philips) with no spacing and 3D Volume reconstruction image and it was obtained in a DICOM CD. Then Stereotactic frame (Z-D Fisher) frame was applied and CT scan head was done (1 slice Siemens with $2 \mathrm{~mm}$ thickness) with no tilt. These images were retrieved in a DICOM CD. Then these two images were fused in the workstation and standard Globus palidus internus was visualized anatomically. The Anterior commisure(AC) and Posterior commisure(PC) was also visualized and AC- PC line was made. The standard functional targets were used for Globus pallidus internus.(2-3 $\mathrm{mm}$ infront of Midcommisural point, 20-22 $\mathrm{mm}$ lateral to midline and $4-6 \mathrm{~mm}$ below ACPC line) The targets were also reverified by the inbuilt Schaltenbrand Atlas. Then the patients were taken to the operating room and the frame was fixed in the Mayfield.

Under all aseptic precautions local anesthesia was given on the scalp and vertical incision was given $(4 \mathrm{~cm}$ lateral to midline and $1 \mathrm{~cm}$ in front of coronal suture). A burr holes was created and dura was coagulated and cut and technique were used so as to prevent the loss of cerebrospinal fluid (CSF) thus brain shift is minimized. The thermal lesioning machine of Cosman RF generator/ N50 RF generator was used and the voltage, impedance and rate of the thermal coagulation were set. The lesioning electrode of $1 \mathrm{~mm}$ diameter and $2 \mathrm{~mm}$ exposed tip was used. All the cases except the first one also underwent MER Recording (Microelectrode recording, Inmito). We
Pallidotomoy in Parkinson's Disease

used 2-3 MER electrode in each case aligned diagonally) and recording were started $6 \mathrm{~cm}$ above the target. The targets were set and it was checked by $\mathrm{C}$-arm. Usually the test dose of 50 degree centigrade for $30 \mathrm{sec}$ was used and we made sure that there are no motor deficits. Then two lesions were made $1 \mathrm{~mm}$ apart (70 degree centigrade for 40 second each. Continuous communication to the patients was done to make sure that there is no motor symptoms and visual symptoms.

\section{Results}

There were five patients who underwent posteroventral pallidotomy. All patients were male patients. Two of them were farmers, two were teachers and one was government officer. The median age was $50.2 \pm 12.2$ years as shown in Table 1. The median duration of illness was $6 \pm 1.9$ years. Out of five cases, three cases underwent bilateral pallidotomy. Among them one case had staged bilateral pallidotomy with three months gap in between two pallidotomies (Figure2). The remaining two cases had unilateral pallidotomy (Figure 1) out of which one was for tremor dependent hemiparkinsonism one is the remaning case of staged pallidotomy. The median change in UPDRS was $63.7 \pm 11 \%$ in postoperative time and it was statistically significant as shown in Table 2.

One patient of unilateral pallidotomy developed Parkinsons crisis and he had to be admitted in intensive care unit for 10 days and finally he got better. He is yet to go to staged pallidotomy in future. One of the cases of bilateral Pallidotomy developed mild dysarthia but is getting better. There were no major complications like postoperative hemorrhage and infection. We have median follow up of $12 \pm 7.7$ months as shown in Table 3. There is no change in the Dopamine dosage and the improvement of UPDRS has not decreased much in follow up period.

\begin{tabular}{|l|l|l|l|l|l|}
\hline SN & Age & Sex & $\begin{array}{l}\text { Duration } \\
\text { of illness } \\
\text { (Yrs) }\end{array}$ & Occupation & Address \\
\hline 1 & 36 & Male & 8 & Teacher & Chitwan \\
\hline 2 & 60 & Male & 6 & Teacher & Kathmandu \\
\hline 3 & 50 & Male & 6 & Farmer & Butwal \\
\hline 4 & 47 & Male & 3 & $\begin{array}{l}\text { Government } \\
\text { officer }\end{array}$ & Kathmandu \\
\hline 5 & 68 & Male & 4 & Farmer & Dang \\
\hline
\end{tabular}

Table 1: Showing demographics of the patients 


\section{Shrestha et al}

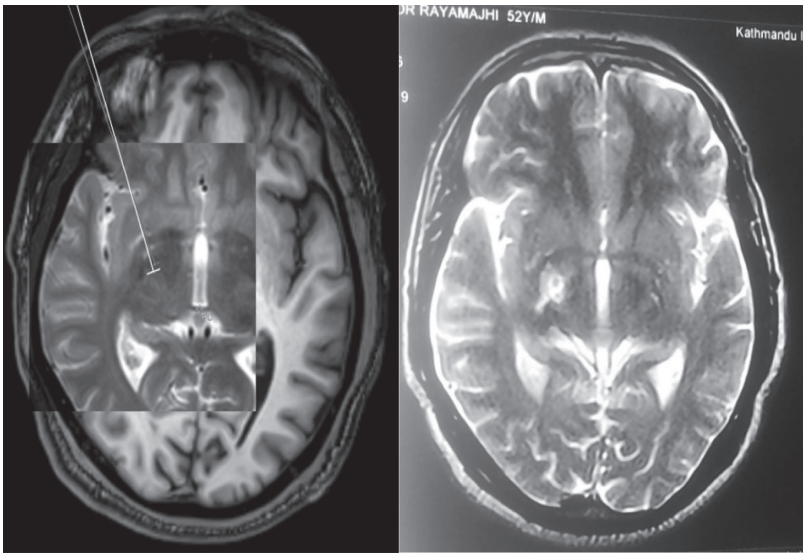

Figure 1 : showing preoperative targeting of Right GPI in T1/T2 fusion MRI and Postoperative T2W MRI of same patient showing Right pallidotomy with perilesional edema

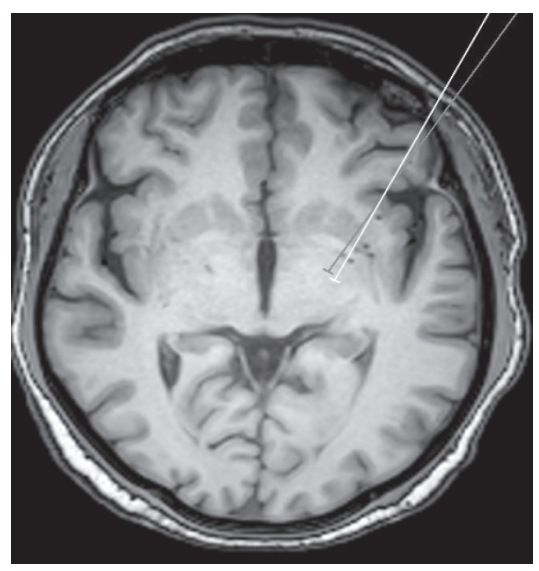

Figure 2 : showing preoperative targeting of the Left $G P i$ and we can see the previous lesion in the right GPi region in a case of staged bilateral GPi palliodotomy

\begin{tabular}{|l|l|l|l|l|l|l|}
\hline SN & Target & & $\begin{array}{l}\text { Preop } \\
\text { UPDRS }\end{array}$ & Postop UPDRS & $\begin{array}{l}\text { Change in } \\
\text { UPDRS(\%)* }\end{array}$ & Remarks \\
\hline 1 & Gpi & Bilateral & $58 / 147$ & $20 / 147$ & 63.79 & Improved \\
\hline 2 & Gpi & Unilateral & $56 / 147$ & $22 / 147$ & 60.71 & Parkinsons crisis but got better \\
\hline 3 & Gpi & Staged Bilateral & $58 / 147$ & $13 / 147$ & 77.59 & Improved \\
\hline 4 & Gpi & Unilateral & $56 / 147$ & $11 / 147$ & 80.36 & Improved \\
\hline 5 & Gpi & Bilateral & $42 / 147$ & $19 / 147$ & 54.76 & Improved with mild dysarthia \\
\hline
\end{tabular}

* P value less than 0.05 in Wilcoxon sign rank test

Table 2: Showing the site of lesion and change in UPDRS

\begin{tabular}{|r|l|l|l|l|}
\hline SN & Target & & Follow up period & Change in Dopamine dosage \\
\hline 1 & Gpi & Bilateral & 2 years & No \\
\hline 2 & Gpi & Unilateral & 1 year & No \\
\hline 3 & Gpi & Staged Bilateral & 1 year & No \\
\hline 4 & Gpi & Unilateral & 8 months & No \\
\hline 5 & Gpi & Bilateral & 3 months & No \\
\hline
\end{tabular}

Table 3: showing the duration of follow up and the change in the dopamine dosage

\section{Discussion}

Pallidotomy has improved many symptoms of Parkinsons disease like tremor, rigidity and dyskinesia in short term follow up. ${ }^{12,15,16,18}$ The percentage reduction in UPDRS Part III motor score has ranged from $25-35 \%$ in 6 months follow up ${ }^{8,11}$ however it has somewhat decreased to $15-25 \%$ in more than two years follow up..$^{14,6,7}$ Though our mean follow up is about one year, all the patients have sustained the benefit of pallidotomy till now and it is quite comparable. We have also started Microelectrode recording(MER) for localizing the GPi in all the recent cases and we have found it to be a helpful tool for the electrophysiological localization. However we only use three MER Probe in diagonal fashion to decrease the probe related intraoperative hematoma which has been reported in the literature. ${ }^{1}$

We had to do simulataneous bilateral pallidotomies in two cases who denied staged surgery. One of the patients had mild dysarthia but it is getting better. Otherwise there are no other major complications of this procedure. However there is increased risk of negative affection of speech, swallowing and cognition defect in bilateral pallidotomy. ${ }^{20}$ Patients whom we did stage bilateral 
palldotomy had no such complication. One patient of planned stagged unilateral pallidotomy developed Parkinsons crisis postoperatively but eventually recoverd. This is a rare complication and we believe that it is because of prolonged withdrawal of syndopa(48hours) before surgery due to technical issues. So we have decided to stop syndopa for only 6 hours before surgery and we immediately start it postoperatively. This patient has not undergone another lesioning procedure.

It is often argued pallidotomy should be abandoned as Deep brain stimulation is safer, can be performed bilaterally and is reversible. ${ }^{2}$ But Delong argued that it is less expensive, doesnot require battery replacement and is without risk of infections and hardware related complications. $^{5}$ It also does not require time consuming adjustment of stimulating parameters. Pallidotomy is certainly not as safe as DBS if performed simultaneously and bilaterally but evidence show that result of unilateral pallidotomies are still better for patients with advanced PD than medications alone. ${ }^{19,4}$ Sometimes its result is still safe and comparable with STN DBS. ${ }^{3}$

All of our patients did not have any changes in the dose of dopaminergic medications. It was well tolerated by all the patients even by elderly patients as we do not require general anesthesia. We believe that lesioning procedure is cheaper for the patients. Most of our patients of lesioning are from outside Kathmandu valley and they require less frequent follow up as compared to our patients with DBS.

\section{Conclusion}

The result of pallidotomy for Parkinsons disease is quite promising but we would like to do unilateral pallidotomy or staged bilateral pallidotomies to decrease the risk of speech disorder and cognition. We believe that pallidotomy may surpass DBS in our setup due to affordability, no need of time consuming adjustment of battery parameters and no hardware related complications. Proper selection of patients is a must and MER also guides intraoperatively for proper localization of the targets. However increased number of patients and long term follow up is needed to prove the statement.

\section{Acknowledgement}

We would like to specially acknowledge out Biomedical engineers Mr Vipin Tyagi, Mr Saurab Basist and Mr Kishor Bhandari for their technical assistance during the procedure.

\section{Pallidotomoy in Parkinson's Disease Reference}

1. Alkhani A, Lozano AM. Pallidotomy for Parkinsons Disease: a review of contemporary literature. J.Neurosurg 94:43-9, 2001

2. Benabid AL, Why should we abandon pallidotomy? Moving along 3:3-5, 2001

3. Blomsted P, Hariz MI. Are complications less common in deep brain stimulation than in ablative procedures for movement disorders. Stereotact Funct Neurosurg 84:72-81, 2006

4. De Bie RM, De Haan RJ, Nijsen PC et al. Unilateral pallidotomy in Parkinsons disease: a randomized single blind multicenter trial. Lancet 354:16651669, 1999

5. Delong MR. Why pallidotomy should not be abandoned? Moving along 3:3, 2001

6. Dewey Jr RB, Giller CA, Broline SK, et al. Clinical outcome of unilateral stereotactic pallidotomy without microelec-trode recording for intractable Parkinsonson's disease. Parkinsonism and Related Disorders 6:7-17, 2000

7. Fine J, Duff J, Chen R, Chir B, Hutchison W, Lozano AM, et al. Long term follow up of unilateral pallidotomy in advanced Parkinsons Disease. N Engl J Med 342:1708-1714, 2000

8. Giller CA, Dewey RB, Ginsburg MI, Mendelsohn DB, Berk AM. Stereotactic pallidotomy and thalamotomy using individual variations of anatomic landmarks for localization. Neurosurgery 42:56-65, 1998

9. Guiot G, Brion S. Traitement des mouvements anormaux par la coagulation pallidale. Rev Neurol(Paris) 89: 578-580, 1953

10. Iacono RP, Shima F, Lonser RR, et al. The results, indications and physiology of posteroventral pallidotomy for patients with Parkinson's Disease. Neurosurgery 36(6):1118-1127, 1995

11. Kopyov O, Jacques D, Duma C, et al. Microelectrode guided posteroventral medial radiofequency pallidotomy for Parkinsons Disease. J Neurosurg 87:52-59, 1997

12. Laitinen LV, Bergenheim AT, Hariz MI. Leksell's Posteroventral pallidotomy in the treatment of Parkinsons Disease. J Neurosurg 76:53-61, 1992

13. Lozano AM, Lang AE, Galvez-Jimenez N, et al. Effect of GPI pallidotomy on motor function in Parkinson's Disease. Lancet 346:1383-1387, 1995

14. P K Pal, A. Samii, A Kishore, et al. Long term outcome of unilateral pallidotomy: follow up of 15 patients for 3 years. J Neurol.Neurosurg Psychiatry 69:337-344, 2000 


\section{Shrestha et al}

15. Shima F, Ishido K, Sun SJ, et al. Surgical control of akinesia in Parkinson's disease. Eur Neurol 36(suppl 1):55-61, 1996

16. Sutton JP, Couldwell W, Lew MF, et al. Ventroposterior medial pallidotomy in patients with advanced Parkinson's disease. Neurosurgery 36:1112-1117, 1995

17. Svennilson E, Torvik A, Lowe R, Lekshell L. Treatment of parkinsonism by stereotactic thermolesions in the pallidal region. Acta Psychiatr Neurol Scand 35: 358-77, 1960
18. Uitti RJ, Wharen REJ, Turk MF, et al. Unilateral pallidotomy for Parkinson's disease: comparison in younger versus elderly patients. Neurology 49:1072-1077, 1997

19. Vitek Jl, Bakay RA, Freeman A, et al. Randomised trial for pallidotomy versus medical therapy for Parkinsins Disease. Ann Neurol 53:558-569, 2003

20. York MK, Lai EC, Jankovic J, et al. Short and long term motor and cognitive outcome of staged bilateral pallidotomy: a retrospective analysis. Acta Neurochir(Wien) 149:857-866, 2007 